Now Realy, Fourih Edition, Revised and Enlarged, with Lithographic Plates and Wood Engrarings, 8ro., 258.

MANUAL OF PSYCHOLOGICAL MEDICINE.

By J. C. BUCKNILL, M.D., F.R.C.P., F.R.S., and

D. HACK TUKE, X.D., F.R.C.P.

J. \& A. Churchill, New Burlington Street.

8vo., $14 \mathrm{~s}$.

ILLUSTRATIONS OF THE INFLUENCE OF THE MIND UPON THE BODY.

By D. HACK TUKE, M.D., F.R.C.P.

"We commend this work very heartily to our readers as a valuable collection of well-digested facts, suggestive of many useful applications by medical practtioners."-Journal of Mental Science.

J. \& A. Churchir, New Burlington Strect.

Just published, 8vo., 2 s.

\title{
INSANITY AND THE LUNACY LAW.
}

By Wy. WOOD, M.D., F.R.C.P.,

Physician to St. Luke's Hospital, Vice-President of the Royal Medical and Chirurgical Society, formerly Principal Resident Officer at Bothlehem Hospital.

J. \& A. CuurcniLt, New Burlington Street.

Vow really, with 16 Plates and 26 Woodcuts, comprising 112 original Illustrations of the Changes in the Eye in Diseases of the Brain, Kidneys, \&c., 8vo., 18s.

A MANUAL \& ATLAS of MEDICAL OPHTHALMOSCOPY.

By W. R. GOWERS, M.D., F.R.C.P.,

Assistant-Professor of Clinical Medicine in University College.

J. \& A. Chtrceill, New Burlington Street.

Price 1s. 6d. Monthly.

'THE PRACTITIONER : a Journal of Therapeutics and Public Health.

Edited by T. LAUDER BRUNTON, M.D., F.R.S., Fellow of the Royal College of Physicians; Assistant Physician to St. Bartholomew's Hospital; and Lecturer on Materia Medica and Therapeutics in St. Bartholomew's Hospital School.

YACMILLAX AXD CO., 29 \& 30, Bedford Street, Covent Garden, London. 


\title{
CONYRETS OF No. 108.-JAYUUARY, 1879.
}

\author{
PART I.-ORIGINALARTICLES.
}

Winiem W. Treiand, M.D. On Thought withoat Worts, and the Relation of Words to

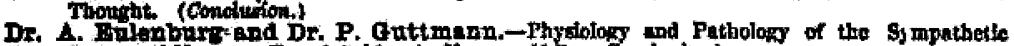

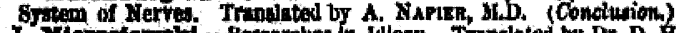

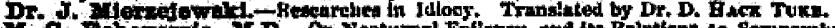

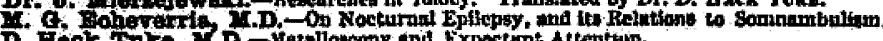

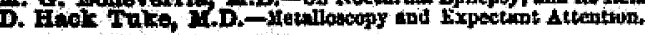

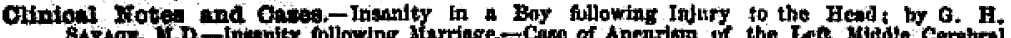

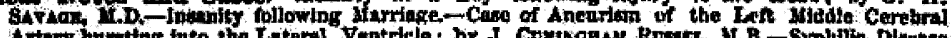

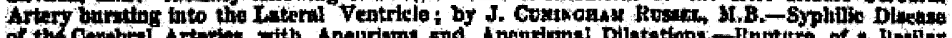
of the Cerobiral Arteries,

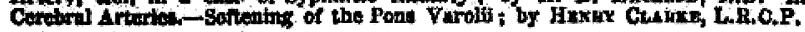

Oodatonst Xotes of the Quarter,-Hypoderinis Injection of Marplita.

$$
\text { PART It--REVIEWS. }
$$

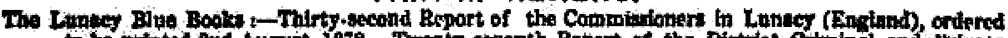

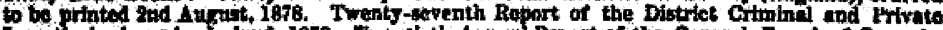

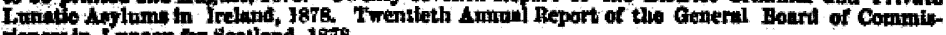

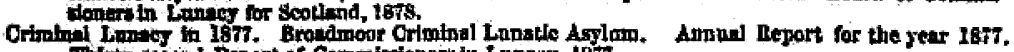

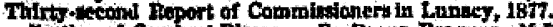

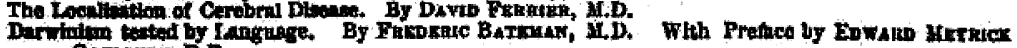

On the Uos of Ed D.D.

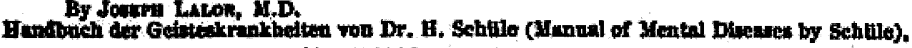

PART III.-PSYCHOLOGIOAL. RETROSPECT.

1. French Retroopect. By J. G. YoDowath, M.B.

PART IV.-NOTES AND NEWS.

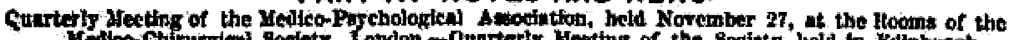

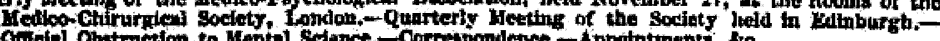

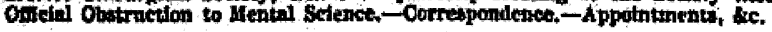

CONTEITS of No. 109.-APRI, 1879.

PART I.-ORIGINAL ARTICLES.

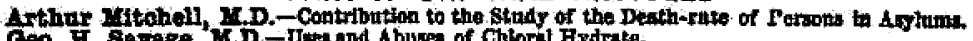

Geo. H. Serate, M.D. - Umes apd Abusea of Chloril Hydrate.

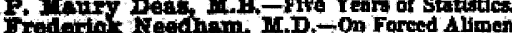

Froderto. Aleatham, M.D. - On rareed Alimentatlom.

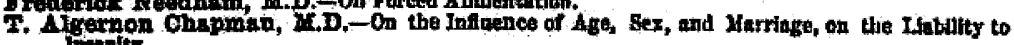

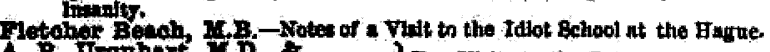

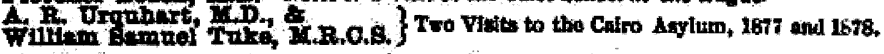

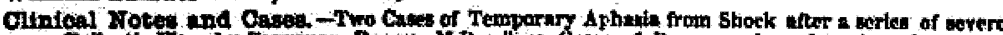

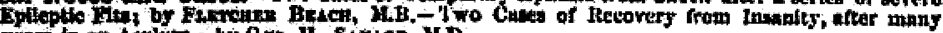
jows to an Asylum ; by Qw. H. Sirsae, M.D.

Ocentonal Motes of the Quarter.-Insants nssoctuted with an Abects connected with the

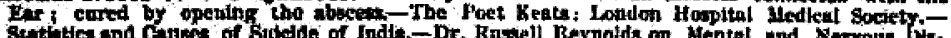

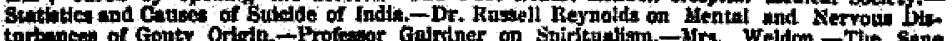

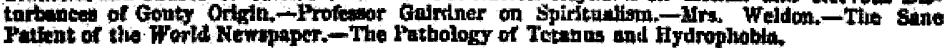

PART II.-REVIEWS.

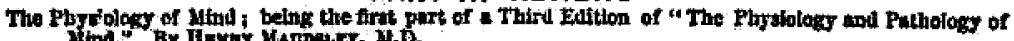

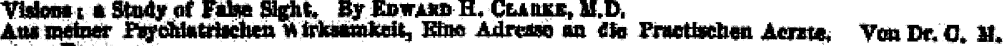

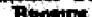

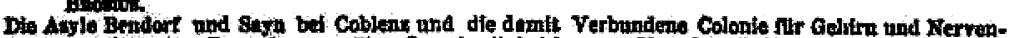

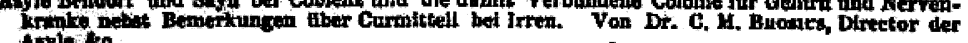
A tola ko.

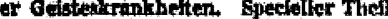

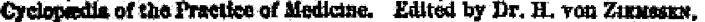

PART III.-PSYCHOLOGICAL RETROSPECT.

3. Gerpinan Retrospeot. By W. ImELaxD, M.D.

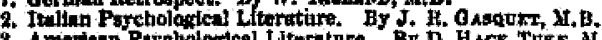

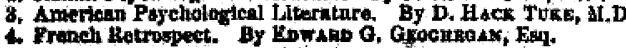

PART IV.-NOTES AND NEWB.

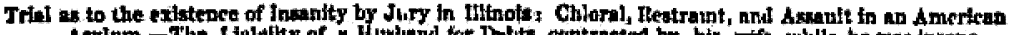
A

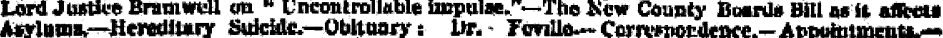
intox to Vol. xitio, \&s. 


\section{JOURNAL OF MENTAL SCIENCE.}

JULY, 1879.

OONTENTS.

PART I,-ORIGINAL ARTICLES.

Samuel Wilks, M.D.-Notes from the History of my Parrot, in reference to the Nature of Language.

Herbert C. Major, M.D.-Case of Paralytic Idiocy, with right-sided Hemiplegia ; Epilepsy ; Atrophy with Sclerosis of the Left Hemisphere of the Cerebrum and of the Right Lobe of the Cerebellum.

Frederic Norton Manning, M.D.-Statisties of Insanity in Australia.

George H. Savage, M.D,-Hyoseyamine and its Uses.

William W. Ireland, M.D.-The History of the Hereditary Neurosis of the Royal Family of Spain.

William Macleod, M.D.-Two Cases of General Paralysis.

D. Hack Tuke, F.R.C.P.-Notes on Criminal Lunacy in France.

Clinical Notes and Cases.-Case of General Paralysis, with Extreme Incoordination and Muteness; by J. CarLYLE JoHNstone, M.B.-Three Cases of Mental Disease accompanied by Affection of the Bones of the Skull; by Dr. Crousion.-Fatty Embolism of the Vessels of the Lungs in an Epileptic who had died Comatose after a succession of Fits; by Di. Crouston.

Occasional Notes of the Quarter.-Lunacy Legislation. PART II.-REVIEWS.

The Pathology of Mind. By Henry Maudshey, M.D.

The Life of George Combe. By Chartes Grbbon.

Hume. By Professor Huxinx.

A New Theory of Trance and its Bearings on Human Testimony. By George Beard, M.D.

Philosophical Fragments. By J. D. Monrel, LL.D.

PART III.-PSYCHOLOGICAL RETROSPECT.

1. German Retrospect. By Writram W. Imidand, M.D.

2. American Retrospect. By D. Hack Tuke, M.D.

3. English Retrospect. Einglish and Scotch Asylum Reports for 1878, PART IV. - NOTES AND NEWS.

Quarterly Meeting of the Medico-Psychological Association, held March 19, in Berners Street, London, - Quarterly Meeting in Glasgow, March 26. -Morison Lectures on Insanity.-The Lectureship on Mental Diseases in the University of Edinburgh.-Appointments, \&c.

The Editors do not hold themselves responsible for the views of Contributors whose names are signed.

No. CXI. (New Series, No. 75) will be published on the 1 st of October, 1879. 